\title{
Implementasi Pemanfaatan dan Pengelolaan Keuangan Dana Kapitasi JKN Oleh Fasilitas Kesehatan Tingkat Pertama (FKTP) Pemerintah Kota Kotamobagu
}

\author{
RINNY FADLILAH MOKODOMPIT ${ }^{1}$, DAVID P. E SAERANG ${ }^{2}$, HENDRIK MANOSSOH ${ }^{3}$
}

\author{
${ }^{1,2,3}$ Program Magister Akuntansi, Fakultas Ekonomi dan Bisnis Universitas Sam Ratulangi \\ email: rinnymokodompit@ymail.com ${ }^{1}$, dpesaerang@gmail.com ${ }^{2}$, hendrik_manossoh@yahoo.com ${ }^{3}$
}

\begin{abstract}
The Implementation of National Health Insurance (NHI) has been started in Indonesia since 2014. BPJS Health has been appointed as the organizer of NHI and First-rate Health Facilities as the implementers of NHI. In its implementation, FRHF will obtain direct payment from BPJS which will be paid in advance without taking into account the type and amount of health services provided known as NHI capitation fund. The utilisation and management of NHI capitation funds by FRHF municipal government of Kotamobagu in its implementation encountered several obstacles that impact on health services. The purpose of this research is to analyze the implementation process of utilization and financial management of NHI capitation fund by FRHF municipality and to analyse any constraints encountered in the implementation of utilisation and management of NHI capitation fund by FRHF Kotamobagu. This research is a qualitative exploratory study. The object of this research was the local government of Kotamobagu and its BPJS Health office. Data were obtained through indepth interviews, observations, and documentation studies. The informants were selected purposively in order to obtain the correct and accurate information. Interviews were conducted using semi-structured in-depth interviews. The triangulation method was used in testing the validity or credibility of data or sources. Transcribed data from interview result was analyzed by using the content analysis method and then giving themes/coding and finally by conceptualisation. The results of the interpretation are summarised in the narrative text. The result of the research shows that the process of implementation and administration of financial utilisation of NHI capitation fund by FRHF in Kotamobagu has been implemented in accordance with regulation/guidance. Budgeting process of capitation fund of NHI, FRHF of Kotamobagu is centralised at Health Service Agency and included in Budget Implementation Document (BID/DPA) of Health Service Agency along with another Health Service Agencies' BID. The accountability of the financial management condition of NHI capitation funds is based on presidential regulation number 32 Year 2014 and rules from the Minister of Home Affairs number 900/2280/SJ Year 2014. During the implementation of the NHI capitation fund program in $F R H F$, several obstacles were found namely communication issues, human resources, disposition or attitude and bureaucratic structure.
\end{abstract}

Keywords: National Health Insurance (NHI/JKN), BPJS Health, First-rate Health Facilities (FRHF/FKTP), capitation fund, utilization, management.

\begin{abstract}
Abstrak. Pelaksanaan Jaminan Kesehatan Nasional (JKN) mulai di selenggarakan di Indonesia sejak tahun 2014. BPJS Kesehatan ditunjuk sebagai Badan penyelenggara JKN dan Fasilitas Kesehatan Tingkat Pertama (FKTP) sebagai pelaksana program JKN. Dalam pelaksanaannya FKTP akan mendapatkan pembayaran langsung dari BPJS yang dibayar dimuka tanpa memperhitungkan jenis dan jumlah pelayanan kesehatan yang diberikan yang dikenal dengan nama dana kapitasi JKN. Pemanfaatan dan pengelolaan dana kapitasi JKN oleh FKTP Pemerintah Kota Kotamobagu dalam pelaksanaannya menemui beberapa kendala yang berdampak pada pelayanan kesehatan. Tujuan penelitian ini untuk menganalisis proses implementasi pemanfaatan dan pengelolaan keuangan dana kapitasi JKN oleh FKTP Kota Kotamobagu dan menganalisis kendala apa saja yang ditemui dalam implementasi pemanfaatan dan pengelolaan dana kapitasi JKN oleh FKTP Kota Kotamobagu. Penelitian ini merupakan penelitian kualitatif dengan pendekatan eksploratori. Pemerintah Kota Kotamobagu dan kantor BPJS Kesehatan Kota Kotamobagu sebagai objek penelitian. Data diperoleh melalui teknik wawancara mendalam, pengamatan, dan studi dokumentasi. Informan kunci di tentukan secara purposive untuk mendapatkan hasil informasi yang tepat dan akurat. Wawancara menggunakan In-depth interview jenis semi terstruktur. Metode triangulasi digunakan dalam pengujian validitas atau kredibilitas data atau sumber. Data transkip yang di transcribe dari hasil wawancara dianalisis dengan metode analisis isi kemudian diberi tema/coding dan dilakukan konseptualisasi. Hasil interpretasi disimpulkan dalam teks naratif. Hasil penelitian menunjukkan bahwa proses pelaksanaan dan penatausahaan pemanfataan dan pengelolaan keuangan dana kapitasi JKN oleh FKTP Kota Kotamobagu dilaksanakan dengan baik dan mengacu pada regulasi / pedoman yang ada, Proses penganggaran dana kapitasi JKN FKTP Kota Kotamobagu dilaksanakan tersentralisasi di Dinas Kesehatan dan masuk dalam DPA Dinas Kesehatan bersama-sama dengan anggaran kegiatan dinas kesehatan
\end{abstract}


lainnya. Pertanggungjawaban kondisi pengelolaan keuangan dana kapitasi JKN FKTP Kota Kotamobagu sesuai dengan skema alur pertanggungjawaban dana kapitasi JKN berdasarkan Peraturan Presiden Nomor 32 Tahun 2014, dan Surat Edaran Menteri Dalam Negeri Nomor 900/2280/SJ Tahun 2014. Dan selama di implementasikannya program dana kapitasi JKN di FKTP Kota Kotamobagu menemui beberapa kendala yakni komunikasi, sumber daya manusia, disposisi atau sikap dan struktur birokrasi.

Kata kunci: Jaminan Kesehatan Nasional (JKN), BPJS Kesehatan, FKTP, Dana Kapitasi, Pemanfaatan, Pengelolaan.

\section{Pendahuluan}

Sesuai dengan falsafah dasar negara Pancasila terutama sila ke -5 mengakui hak asasi warga atas kesehatan. Hal ini juga termaktub dalam UUD 45 pasal $28 \mathrm{H}$ dan pasal 34, dan diatur dalam UU No. 23/1992 yang kemudian diganti dengan UU 36/2009 tentang Kesehatan. Dalam UU 36/2009 ditegaskan bahwa setiap orang mempunyai hak yang sama dalam memperoleh akses atas sumber daya di bidang kesehatan dan memperoleh pelayanan kesehatan yang aman, bermutu, dan terjangkau. Sebaliknya, setiap orang juga mempunyai kewajiban turut serta dalam program jaminan kesehatan sosial.

Kesadaran tentang pentingnya jaminan perlindungan sosial terus berkembang sesuai amanat pada perubahan UUD 1945 Pasal 134 ayat 2, yaitu menyebutkan bahwa negara mengembangkan Sistem Jaminan Sosial bagi seluruh rakyat Indonesia. Dengan dimasukkannya Sistem Jaminan Sosial dalam perubahan UUD 1945, kemudian terbitnya Undang-Undang Nomor 40 Tahun 2004 tentang Sistem Jaminan Sosial Nasional (SJSN) menjadi suatu bukti yang kuat bahwa pemerintah dan pemangku kepentingan terkait memiliki komitmen yang besar untuk mewujudkan kesejahteraan sosial bagi seluruh rakyatnya. Melalui Sistem Jaminan Sosial Nasional (SJSN) sebagai salah satu bentuk perlindungan sosial, pada hakekatnya bertujuan untuk menjamin seluruh rakyat agar dapat memenuhi kebutuhan dasar hidupnya yang layak.

Pelaksanaan Jaminan Kesehatan Nasional (JKN) di Indonesia telah memasuki tahun keempat. Seperti halnya reformasi kesehatan lainnya di berbagai negara, pelaksanaan JKN di Indonesia menghadapi berbagai tantangan, dari sisi pemberi layanan kesehatan, pengelola jaminan kesehatan, masyarakat sebagai pengguna, serta pemerintah sebagai regulator program. Berbagai studi telah dilakukan untuk menelaah dampak JKN pada pelayanan kesehatan di Indonesia, namun pemanfaatan hasil studi-studi tersebut untuk menyempurnakan kebijakan masih terbatas. Salah satu faktor yang menyebabkan kurang optimalnya penyusunan kebijakan berbasis bukti (evidence-informed policy) adalah pemangku kebijakan kurang dilibatkan secara langsung dalam proses penelitian.

Untuk mengatasi hal itu dikeluarkan Undang- Undang No.40 tahun 2004, tentang Sistem Jaminan Sosial Nasional (SJSN). UU 40/2004 ini mengamanatkan bahwa jaminan sosial wajib bagi seluruh penduduk termasuk Jaminan Kesehatan Nasional (JKN) melalui suatu Badan Penyelenggara Jaminan Sosial (BPJS), sebagai upaya memberikan perlindungan kesehatan kepada peserta untuk memperoleh manfaat pemeliharaan kesehatan dan perlindungan dalam memenuhi kebutuhan dasar kesehatan. Agar pelaksanaannya dapat berjalan dengan baik, efektif, efisien, transparan, dan akuntabel perlu adanya regulasi atau pedoman pelaksanaan program Jaminan Kesehatan Nasional (JKN) ini, diantaranya Peraturan Menteri Keuangan Nomor 206/PMK.02/2013 Tentang Tata Cara Penyediaan, Pencairan, Dan Pertanggungjawaban Dana Iuran Jaminan Kesehatan Nasional Penerima Bantuan Iuran, Undang -Undang No. 24 Tahun 2011 juga menetapkan, Jaminan Sosial Nasional akan diselenggarakan oleh BPJS, yang terdiri atas BPJS Kesehatan dan BPJS Ketenagakerjaan.

Dana kapitasi JKN merupakan dana yang di transfer secara berkala oleh BPJS yang digunakan dalam pembayaran terhadap Fasilitas Kesehatan Tingkat Pertama (FKTP). Sumber dana kapitasi JKN berasal dari pengelolaan dan pengembangan dana iuran peserta JKN, pembayaran dana kapitasi JKN untuk FKTP dilakukan dimuka setiap bulan tanpa memperhitungkan banyaknya pasien peserta JKN yang berobat dan jenis pelayanan kesehatan yang diberikan oleh FKTP. Besaran dana kapitasi yang diberikan oleh BPJS kesehatan untuk FKTP secara regulasi memberikan kemudahan dalam pengelolaannya yang dapat memberikan dampak positif dan negatif terhadap pelaksanaan JKN di daerah. Hal ini mendorong pemerintah agar penyelenggaraan program JKN dapat diimplementasikan sesuai dengan amanat undang-undang.

Regulasi yang digulirkan oleh Menteri Dalam Negeri melalui Surat Edaran Menteri Dalam Negeri Nomor 900/2280/SJ Tanggal 5 Mei 2014 membuat banyak Kepala Puskesmas, Kepala Dinas 
Kesehatan dan Pejabat Pengelolaan Keuangan Daerah / Bendahara Umum Daerah (BUD) menjadi ragu dan takut akan konsekuensi hukum terhadap cara penatausahaan dan pertanggungjawabannya. Hal tersebut terjadi karena sesuai dengan SE Mendagri tersebut. Dana Kapitasi yang bersumber dari APBN / BPJS ditransfer langsung ke rekening bendahara Puskesmas / FKTP milik Pemerintah Daerah. Namun dana kapitasi tersebut harus tetap dicatatkan dalam Laporan Keuangan Pemerintah Daerah (LKPD) setempat meskipun aliran Dana Kapitasi tersebut tidak melalui rekening Bendahara Umum Daerah (BUD). Selanjutnya karena masuk dalam Laporan Keuangan Pemda maka pertanggungjawaban dana kapitasi tersebut menjadi obyek pemeriksaan oleh Badan Pemeriksa Keuangan (BPK) dalam rangka pemeriksaan Laporan Keuangan Pemerintah Daerah.

Di Kota Kotamobagu pelayanan kesehatan masyarakat pemerintah daerah dilayani oleh 5 (lima) Fasilitas Kesehatan Tingkat Pertama (FKTP) dan 1 (satu) Fasilitas Kesehatan Tingkat Lanjutan (FKTL). Dalam pelaksanaannya masih banyak mengalami kendala, seperti hasil kajian dari KPK yang menjadi perhatian tersendiri terutama terkait masalah regulasi, dan sumber daya manusia dimana dalam pemanfaatan dan pengelolaan keuangan dana kapitasi JKN memberikan kebebasan dan kemudahan lewat penggunaan langsung akan tetapi dalam pelaksanaannya menimbulkan keraguan bagi FKTP dalam pengelolaanya. Jika dilihat dari Peraturan Presiden Nomor 32 tahun 2014 mengatakan bahwa dana kapitasi JKN yang sudah di transfer ke rekening FKTP sudah diakui sebagai pendapatan, dalam artian sudah bisa digunakan langsung, sementara dalam regulasi pengelolaan keuangan daerah diatur bahwa semua penerimaan oleh daerah harus disetor ke kas daerah.

Hal lain yang terjadi adalah masalah obat - obatan dan barang medis habis pakai, sesuai dengan Peraturan Menteri Kesehatan Nomor 19 tahun 2014 yang telah di ubah dengan Peraturan Menteri Kesehatan Nomor 21 Tahun 2016 bahwa pengadaan obat, alat kesehatan, dan bahan medis habis pakai berpedoman kepada formularium nasional dan harga obat yang tercantum dalam e-katalog obat. Hal ini juga memberikan kemudahan dalam pengadaannya, akan tetapi ada beberapa macam obat-obatan yang tidak tercover dalam formularium nasional harus ditanggung oleh peserta JKN di FKTP akibatnya masih banyak didapati tambahan biaya yang dibebankan kepada pasien untuk membeli obatobatan yang tidak masuk dalam Formularium Nasional.

Berdasarkan uraian tersebut penelitian ini dilakukan dengan tujuan untuk menganalisis proses implementasi pemanfaatan dan pengelolaan keuangan dana kapitasi JKN oleh Fasilitas Kesehatan Tingkat Pertama (FKTP) Pemerintah Kota Kotamobagu dan menganalisis kendala apa saja yang ditemui dalam implementasi pemanfaatan dan pengelolaan keuangan dana kapitasi JKN oleh Fasilitas Kesehatan Tingkat Pertama (FKTP) Pemerintah Kota Kotamobagu.

\section{Kerangka Konseptual}

Menurut Ibrahim (2015) kerangka konsep merupakan gambaran atau bangunan utuh suatu penelitian, dan merupakan perpaduan dari berbagai aspek, mulai dari permasalahan, aspek-aspek yang terkait yang hendak diteliti, hingga kemungkinan - kemungkinan lain yang ingin dihasilkan dari keseluruhan proses penelitian. Berdasarkan latar belakang masalah, rumusan permasalahan dan teori yang ada, maka kerangka konseptual dalam penelitian ini adalah sebagai berikut: 
Gambar 3.1

Kerangka Konseptual Penelitian

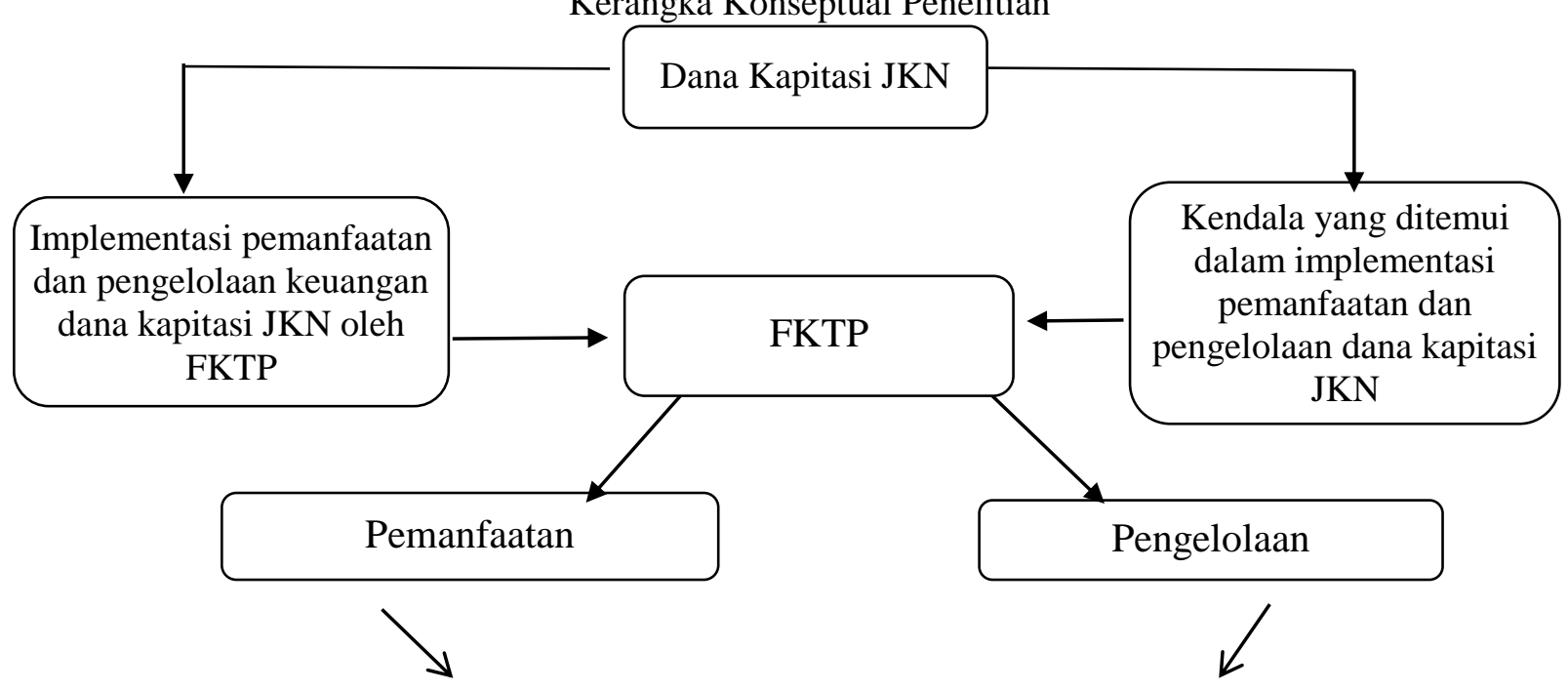

Pelaksanaannya harus sesuai dengan regulasi yang berlaku demi tertibnya administrasi dalam proses pengelolaan keuangan, dalam mewujudkannya harus didukung oleh faktor komunikasi yang efektif dari implementor, sumber daya manusia yang memadai dan sesuai keahlian, disposisi atau sikap dari implementor yang jujur dan memiliki komitmen yang kuat serta sesuai dengan struktur birokrasi yang baik

\section{Metode Penelitian}

Untuk menjawab rumusan masalah mengenai implementasi pemanfaatan dan pengelolaan keuangan dana kapitasi JKN serta kendala yang ditemui, maka penelitian ini menggunakan metode penelitian kualitatif dengan pendekatan eksploratori (exploratory approach). Creswell (2012:206) menjelaskan bahwa dalam penelitian kualitatif, tujuannya adalah tidak untuk menggeneralisasi ke populasi, tetapi untuk mengembangkan eksplorasi mendalam terhadap inti fenomena. Sementara metode eksploratori menurut Arikunto (2010:32), adalah metode penelitian yang bertujuan untuk menggali suatu informasi.

Teknik pengumpulan data yang dilakukan dalam penelitian ini adalah melalui wawancara mendalam (indepth interviews), pengamatan/observasi (observation), dan dokumentasi (documentation). Selanjutnya, uji keabsahan data yang digunakan dalam penelitian ini adalah credibility dan dependability. Wawancara dilakukan kepada 5 orang Kepala FKTP, 5 orang Bendahara FKTP, Kepala Dinas Kesehatan, Kasubag Keuangan dan Perencanaan Dinas Kesehatan, Pengelolan JKN Dinas Kesehatan, Kabid Perbendahraan BPKD dan Kepala BPJS Kesehatan Kota Kotamobagu.

Proses analisis data dalam penelitian ini dilakukan sejak sebelum memasuki lapangan dan selama dilapangan. Dalam hal ini Nasution dalam Sugiyono (2015:89) menyatakan analisis telah dimulai sejak merumuskan dan menjelaskan masalah, sebelum terjun ke lapangan dan berlangsung terus sampai penulisan hasil penelitian. Analisis Sebelum di lapangan dilakukan terhadap data hasil studi pendahuluan atau data sekunder yang akan digunakan dalam menentukan fokus penelitian. Namun demikian fokus penelitian masih bersifat sementara dan berkembang setelah berada di lapangan. Analisis data yang dilakukan pada saat pengumpulan data berlangsung, dan setelah selesai pengumpulan data, diolah dengan prosedur: 1) Membuat transkrip wawancara (interviews transcriptions), 2) melakukan analisis data, dan 3) mengambil kesimpulan dari hasil penelitian.

\section{Analisis dan Pembahasan}

Penelitian ini dilakukan selama 3 (tiga) bulan yakni antara bulan bulan Mei 2017 hingga bulan Juli 2017. Intrumen penelitian pendukung adalah buku catatan (notebook), pedoman wawancara, alat perekam berupa audio recorder (handphone) untuk merekam pelaksanaan wawancara dengan informan yang hasilnya ditranscribe menjadi transkrip data, kamera untuk mendokumentasikan kegiatan penelitian dilapangan, laptop untuk menunjang penulisan hasil penelitian. Selain itu, pengalaman peneliti sebelum melanjutkan studi adalah bekerja sebagai fungsional umum di Dinas 
Kesehatan Kota Kotamobagu selama 2 (dua) tahun menjadi referensi dan informasi dalam memecahkan permasalahan yang diangkat oleh peneliti.

\section{Kepesertaan JKN Kota Kotamobagu}

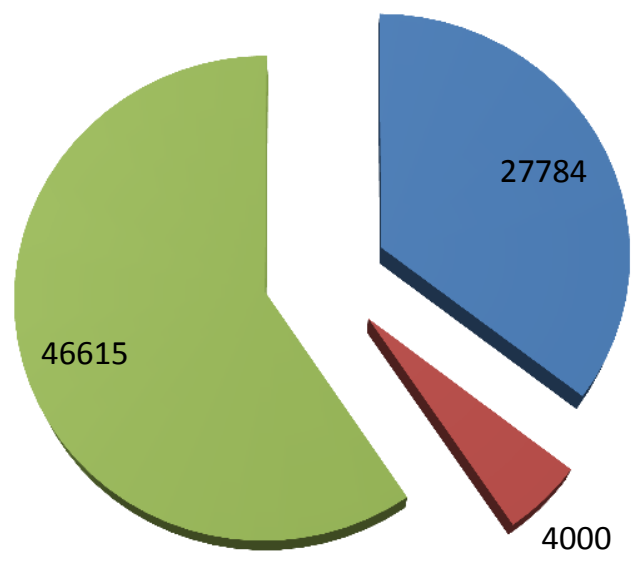

PBI APBN

PBI APBD

NON PBI

Sumber: BPJS Kesehatan Kota Kotamobagu (2017).

Data Fasilitas Kesehatan Yang Bekerja Sama Dengan BPJS Kesehatan Kota Kotamobagu Tahun 2017

Fasilitas Kesehatan Tingkat Pertama (FKTP)

\begin{tabular}{|l|l|c|c|}
\hline No & \multicolumn{1}{|c|}{ Jenis Fasilitas Kesehatan } & Jumlah & Satuan \\
\hline 1 & Puskesmas & 5 & Unit \\
\hline 2 & Praktik Dokter & 7 & Orang \\
\hline 3 & Praktik Dokter Gigi & 1 & Orang \\
\hline 4 & Klinik Pratama & - & Unit \\
\hline 5 & Rumah Sakit Pratama & - & Unit \\
\hline
\end{tabular}

Fasilitas Kesehatan Tingkat Lanjutan (FKTL)

\begin{tabular}{|l|l|c|c|}
\hline No & \multicolumn{1}{|c|}{ Jenis Fasilitas Kesehatan } & Jumlah & Satuan \\
\hline 1 & Klinik Utama atau yang setara & - & Unit \\
\hline 2 & Rumah Sakit Umum & 1 & Unit \\
\hline 3 & Rumah Sakit Khusus & 1 & Unit \\
\hline
\end{tabular}

Sumber: BPJS Kesehatan Kota Kotamobagu (2017)

\section{Pemanfaatan Dana Kapitasi JKN Pada FKTP}

Dana kapitasi JKN yang diterima oleh FKTP Kota Kotamobagu dari BPJS Kesehatan dimanfaatkan seluruhnya untuk pembayaran jasa pelayanan kesehatan dan dukungan biaya operasional pelayanan kesehatan. Penggunaan dana kapitasi JKN diatur oleh Permenkes untuk kemudian diatur oleh Surat Keputusan Kepala Daerah sesuai dengan bunyi pasal 3 point (4) Permenkes 21 Tahun 2016: Besaran alokasi sebagaimana dimaksud ditetapkan setiap tahun dengan Keputusan Kepala Daerah atas usulan Kepala SKPD Dinas Kesehatan Kabupaten/Kota. dengan mempertimbangkan:

a. Tunjangan yang telah diterima dari pemerintah daerah

b. Kegiatan operasional pelayanan kesehatan dalam rangka mencapai target kinerja dibidang pelayanan kesehatan, dan

c. Kebutuhan obat, alat kesehatan, dan bahan medis habis pakai

Pemanfaatan dana kapitasi JKN oleh FKTP Kota Kotamobagu menggunakan dasar Keputusan Walikota No. 20 Tahun 2017 tentang Alokasi Dana Kapitasi JKN Pada FKTP Kota Kotamobagu 
Tahun 2017 dengan pembagian $70 \%$ untuk jasa dan 30\% untuk biaya operasional lainnya (Obat, Alkes, BMHP).

Kepala FKTP, pengelola dan bendahara dana kapitasi JKN di FKTP maupun Dinas kesehatan Kota Kotamobagu memahami implementasi regulasi yang mengatur pemanfaatan dana kapitasi JKN yaitu Peraturan Menteri Kesehatan Nomor 21 Tahun 2014 dan Peraturan Menteri Kesehatan Nomor 28 Tahun 2014, dimana dana kapitasi JKN ini semata-mata bermanfaat untuk peningkatan derajat kesehatan masyarakat secara menyeluruh (komprehensif) sesuai dengan standar pelayanan medik yang cost effective dan rasional serta menciptakan pelayanan terstruktur, berjenjang dengan portabilitas, ekuitas, efisien, transparan dan akuntabel. Hal ini juga sejalan dengan apa yang disampaiakn dalam Teori Keadilan oleh Mill dikutip oleh Lebacqz (1986) "Keadian bagi Mill mensyaratkan aturan aturan yang ditetapkan menjadi kebaikan masyarakat demi menjamin pemenuhan kewajiban kewajiban tertentu yang keras dan demi melindungi hak - hak individu".

\section{Pengelolaan Dana Kapitasi JKN Pada FKTP}

\section{Penganggaran}

Peraturan Presiden Nomor 32 Tahun 2014 bagian kedua mengatur mengenai penganggaran, pada pasal 4 yaitu:

1. Kepala FKTP menyampaikan rencana pendapatan dan belanja dana kapitasi JKN tahun berjalan kepada Kepala SKPD Dinas Kesehatan

2. Rencana pendapatan dan belanja dana kapitasi JKN mengacu pada jumlah peserta yang terdaftar di FKTP dan besaran kapiatsi JKN sesuai dengan peraturan perundang- undangan yang berlaku

3. Rencana pendapatan dan belanja tersebut dianggarkan dalam RKA-SKPD Dinas Kesehatan

Proses penganggaran dana kapitasi JKN di Kota Kotamobagu untuk tahap dan teknik penganggaran mengikuti regulasi yang mengatur tata cara penganggaran dana kapitasi JKN, dimana FKTP membuat dan menyampaikan usulan RKA ke Dinas Kesehatan Kota Kotamobagu dan semua belanja dana kapitasi JKN baik untuk jasa maupun biaya operasional harus sesuai dengan anggaran yang ada di RKA-SKPD Dinas Kesehatan Kota Kotamobagu. Dalam penganggaran sektor kesehatan salah satu sistem yang dipergunakan dalam penganggaran adalah metode incremental budgeting. Menurut Bastian (2015:403) incremental budgeting adalah sistem anggaran belanja dan pendapatan yang memungkinkan revisi selama setahun berjalan sekaligus sebagai dasar penentuan usulan anggaran periode tahun yang akan datang. Angka di pos pengeluaran kesehatan merupakan perubahan (kenaikan) dari angka periode sebelumnya.

\section{Pelaksanaan dan Penatausahaan}

Pelaksanaan Jaminan Kesehatan Nasional (JKN) di Kota Kotamobagu dilaksanakan oleh BPJS Kesehatan sebagai pelaksana Sistem Jaminan Kesehatan Nasional (SJSN) dengan Dinas Kesehatan Kota Kotamobagu melalui Perjanjian Kerja Sama Nomor 198 / KTR / X-06 / 1216 dan Nomor 400 / Dinkes-KK / 2495 / XII / 2016. Dalam perjanjian tersebut menyebutkan bahwa membayar dana kapitasi kepada pihak kedua paling lambat tanggal 15 (lima belas) bulan berjalan. Sebelum dana dicairkan setiap FKTP membuat rincian belanja sesuai pendapatan dan dimasukan ke dinas kesehatan untuk mendapatkan surat rekomendasi pencaiaran dari Kepala Dinas Kesehatan Kota Kotamobagu, ini merupakan salah satu bentuk pengawasan dari Dinas Kesehatan untuk meyakinkan efektivitas, efisiensi dan akuntabilitas pengelolaan dan pemanfaatan dana kapitasi JKN.

Dalam pelaksanaan program dana kapitasi JKN harus dikelola secara efektif dan efisien dan dilaksanakan secara terkoordinasi dan terpadu dari berbagai pihak terkait baik pusat maupun daerah. Dan diharapkan pelayanan kesehatan dapat dilaksanakan dengan sebaik - baiknya untuk mewujudkan peningkatan derajat kesehatan masyarakat seutuhnya. Hal ini sejalan dengan apa yang disampaikan oleh Edison (2016:41) untuk mendukung proses implementasi agar tujuan jangka pendek dapat terwujud dengan baik harus didukung oleh tata kelola. Tata kelola mendorong pengelolaan perusahaan yang professional dengan cara meningkatkan prinsip keterbukaan, akuntabilitas, dan efektifnya sistem pengendalian internal.

\section{Pertanggungjawaban}

Kondisi pengelolaan keuangan dana kapitasi JKN oleh FKTP Kota Kotamobagu sesuai dengan skema aliran pertanggungjawaban dana kapitasi JKN berdasarkan Perpres 32 Tahun 2014, dimana Kepala FKTP bertanggung jawab secara formal dan material atas pendapatan dan belanja dana kapitasi 
JKN. Kepala SKPD Dinas Kesehatan menyusun laporan realisasi pendapatan dan belanja yang bersumber dari dana kapitasi JKN berdasarkan SP2B FKTP, serta menyajikannya dalam Laporan Keuangan SKPD Dinas Kesehatan yang akan dikonsolidasikan menjadi Laporan Keuangan Pemerintah Daerah sesuai dengan ketentuan peraturan perundang-undangan di bidang pengelolaan keuangan daerah.

Bentuk pertanggungjawaban sangatlah diperlukan dalam suatu organisasi pemerintah terutama dalam hal pengelolaan keuangan yang berorientasi kepada publik. Seperti yang disampaikan oleh Simbolan (2006) "Akuntabilitas adalah kewajiban untuk menyampaikan pertanggungjawaban atau untuk menjawab dan menerangkan kinerja dan tindakan seseorang / badan hukum atau pimpinan kolektif atau organisasi kepada pihak yang dimiliki hak atau berkewenangan untuk meminta keterangan atau pertanggungjawaban" sedangkan menurut Sedarmayanti (2003) "Akuntabilitas adalah suatu perwujudan kewajiban untuk mempertanggungjawabkan keberhasilan atau kegagalan pelaksanaan misi organisasi dalam mencapai tujuan dan sasaran yang telah ditetapkan melalui media pertanggungjawaban yang dilaksanakan secara periodik.

\section{Skema aliran pertanggungjawaban Dana Kapitasi BPJS}

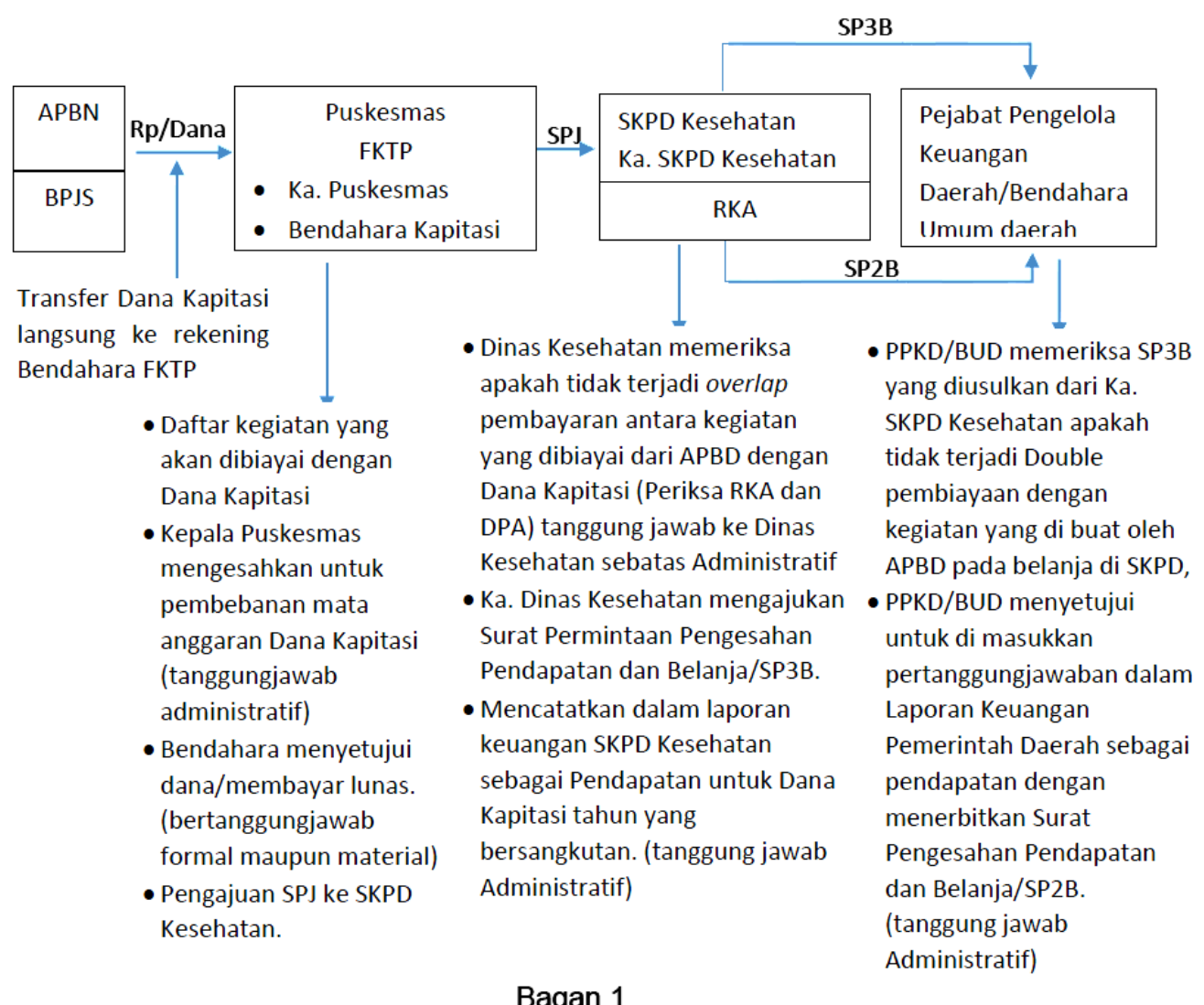

\section{Kendala Yang Ditemui Dalam Implementasi Pemanfaatan Dan Pengelolaan Keuangan Dana Kapitasi JKN Oleh FKTP \\ 1. Komunikasi}

Kendala yang terjadi dilapangan terkait komunikasi yakni bahwa FKTP kurang menerima informasi dari pihak BPJS dalam hal pendanaan maupun kepesertaan, serta kurangnya sosialisasi program JKN kepada masyarakat, sehingga pemanfaatan dan pengelolaan dana kapitasi JKN belum efisien akibat tidak efektifnya suatu komunkasi. Komunikasi adalah hubungan kontak antar dan antara manusia baik individu maupun kelompok. Dalam kehidupan sehari-hari disadari atau tidak komunikasi adalah bagian dari kehidupan manusia itu sendiri.

Menurut Edward (1980) salah satu variabel yang memperngaruhi implementasi kebijakan yaitu komunikasi (communications). Nugroho (2014:657) mengatakan implementasi kebijakan pada prinsipnya adalah cara agar sebuah kebijakan dapat mencapai tujuannya. Tidak lebih dan tidak kurang. 
Agar implementasi berjalan efektif, siapa yang bertanggungjawab melaksanakan sebuah keputusan harus mengetahui apakah sebuah implementasi dapat terlaksana.

\section{Sumber Daya Manusia}

Dari hasil penelitian terdapat 2 aspek yang sangat berperan sehingga SDM menjadi salah satu kendala dalam implementasi pemanfaatan dan pengelolaan keuangan dana kapitasi JKN oleh FKTP Kota Kotamobagu. Pertama, kualitas ASN, semua bendahara dana kaptasi JKN di FKTP Kota Kotamobagu tidak sesuai dengan keahlian atau latar belakang pendidikan sehingga mengakibatkan bendahara dana kapitasi kurang paham akan tugasnya. kedua, ASN pada FKTP khususnya bendahara dana kapitasi JKN masih merangkap tugas/kerja dalam mengelola keuangan dana kapitasi JKN.

Hal ini sejalan dengan apa yang disampaikan dalam Theory Stewardship oleh Donaldson dan David (1991) teori stewardship menggambarkan situasi dimana manajemen tidaklah termotivasi oleh tujuan - tujuan individu tetapi lebih ditujukan pada sasaran hasil utama mereka untuk kepentingan organisasi. Teori tersebut mengasumsikan adanya hubungan yang kuat antara kepuasan dan kesuksesan organisasi. Teori stewardship dibangun diatas asumsi filosofis mengenai sifat manusia yakni bahwa manusia pada hakekatnya dapat dipercaya, mampu bertindak dengan penuh tanggung jawab, memiliki integritas dan kejujuran terhadap pihak lain. Dengan kata lain teori stewardship memandang manajemen sebagai dapat dipercaya untuk bertindak dengan sebaik-baiknya bagi kepentingan publik maupun stakeholder. Permasalahan tersebut berdampak pada ukuran kinerja ASN yang ditampilkan menjadi hasil kerja dalam bentuk kualitas maupun kuantitas pada organisasi yang mereka tempati.

\section{Disposisi atau Sikap}

Sikap yang dimiliki oleh para ASN sangat berpengaruh terhadap berhasil tidaknya implementasi kebijakan. Disposisi adalah watak atau karakteristik yang dimiliki oleh implementor seperti komitmen, kejujuran, dan sifat demokrasi. Hasil yang didapat dalam penelitian ini adalah implementasi pemanfaatan dan pengelolaan keuangan dana kapitasi JKN oleh FKTP di Kota Kotamobagu dipengaruhi oleh disposisi atau sikap. Pertama, komitmen pimpinan terhadap regulasi. Kedua, proses pencairan dana kapitasi JKN masih terikat dengan Dinas Kesehatan. Ketiga, kurangnya perhatian dari implementor dalam keaktifan kartu JKN.

Salah satu variabel yang mempengaruhi efektifitas implementasi kebijakan menurut teori Edward III (1980) adalah sikap atau disposisi implementor. Jika implementor setuju dengan bagianbagian isi dari kebijakan maka mereka akan melaksanakan dengan senang hati tetapi jika pandangan mereka berbeda dengan pembuat kebijakan maka proses implementasi akan mengalamai banyak masalah. Ada tiga bentuk sikap / respon implementor terhadap kebijakan, yaitu kesadaran pelaksana, petunjuk / arahan pelaksana untuk merespon program kearah penerimaan atau penolakan, dan intensitas dari respon tersebut.

\section{4. $\quad$ Struktur Birokrasi}

Dalam pelaksanaan Jaminan Kesehatan Nasional (JKN) yang telah memasuki tahun ke empat, dari tahun ke tahun FKTP Kota Kotamobagu banyak menghadapi bebagai kendala struktur birokrasi, dari sisi pengelolaan keuangan, penyerapan anggaran, maupun pemberi layanan kesehatan. walaupun sumber-sumber untuk melaksanakan suatu kebijakan tersedia atau para pelaksana mengetahui apa yang seharusnya dilakukan dan mempunyai keinginan untuk melaksanakan suatu kebijakan, kemungkinan kebijakan tersebut tidak dapat terlaksana atau terealisasi karena terdapatnya kelemahan dalam struktur birokrasi. Ditahun 2014 dan 2015 bermasalah dalam penyusunan anggaran, semua belanja tidak tertata dalam RKA (masih gelondongan) dan terjadi penumpukan anggaran ditahun 2014. Masalah yang terjadi ditahun 2016 yaitu terdapat sisa anggaran untuk pembayarn jasa pelayanan dan belanja obat. Dana kapitasi tersebut masih berada di masing - masing rekening FKTP. Penyebab tidak terealisasinya anggaran untuk jasa pelayanan pada FKTP Kota Kotamobagu di tahun 2016 disebabkan karena kelebihan pagu anggaran dana kapitasi tersebut. Sedangkan untuk belanja obat masih bermasalah dengan pengadaan obat lewat E-Katalog.

Edward III (dalam Subarsono, 2011: 90-92) Struktur organisasi yang bertugas mengimplementasikan kebijakan memiliki pengaruh yang signifikan terhadap implementasi kebijakan. Aspek dari struktur organisasi adalah Standard Operating Procedure (SOP) dan fragmentasi. Struktur organisasi yang terlalu panjang akan cenderung melemahkan pengawasan dan menimbulkan red-tape, yakni prosedur birokrasi yang rumit dan kompleks, yang menjadikan aktivitas organisasi tidak fleksibel. 


\section{Penutup}

1. Proses implementasi pemanfaatan dan pengelolaan keuangan dana kapitasi JKN oleh FKTP Kota Kotamobagu dapat dilihat dari beberapa aspek yaitu:

a. Dalam upaya memberikan pemahaman program Jaminan Kesehatan Nasional (JKN) kepada seluruh stakeholder terkait, sehingga pengimplementasian dana kapiatasi JKN dapat berjalan dengan baik, efektif, efisien, transparan dan akuntabel maka mekanisme implementasi program Jaminan Kesehatan Nasional (JKN) ditetapkan dan dicantumkan dalam guideline program kebijakan. Serta lingkup pelayanan dan pengalokasian dana kapitasi JKN didasarkan sesuai dengan regulasi / pedoman yang ada.

b. Proses Pengelolaan dana kapitasi JKN mulai dari penganggaran, pelaksanan dan penatausahaan serta pertanggungjawaban dilaksanakan dengan baik dan mengacu pada Peraturan Presiden Nomor 32 Tahun 2014 dan Peraturan Menteri Kesehatan Nomor 21 Tahun 2016 serta Surat Edaran Menteri Dalam Negeri Nomor 900/2280/SJ tahun 2014. Dimana dalam proses penganggaran sudah tersentralisasi dengan Dinas Kesehatan dan masuk dalam DPA Dinas Kesehatan bersama-sama dengan anggaran kegiatan dinas kesehatan lainnya, dan untuk pertanggungjawaban dilaksanakan sesuai dengan skema alur pertanggungjawaban dana kapitasi JKN.

2. Walaupun proses implementasi pemanfaatan dan pengelolaan keuangan dana kapitasi JKN oleh FKTP Kota Kotamobagu sudah berjalan dengan baik dan mengacu pada aturan yang ada, akan tetapi masih ditemui kendala yaitu Sumber Daya Manusia (SDM) dan Struktur Birokrasi.

a. Sumber Daya Manusia (SDM) merupakan elemen penting dan merupakan asset terpenting dalam mewujudkan implementasi kebijakan. Dalam pemanfaatan dan pengelolaan keuangan dana kapitasi JKN oleh FKTP Kota Kotamobagu manusia memiliki peran dan fungsi penting dalam aspek komunikasi, sikap atau disposisi maupun kualitas SDMnya. Kurangnya komunikasi dan informasi dari pihak BPJS kesehatan ke FKTP Pemerintah Kota Kotamobagu, kurangnya perhatian dari implementor dan komitmen pimpinan terhadap regulasi dana kapitasi JKN serta kualitas SDM yang belum memadai membuat proses implementasi dana kapitasi JKN menjadi tidak efektif.

b. Struktur Birokrasi dalam pelaksanaan Jaminan Kesehatan Nasional (JKN) oleh FKTP Kota Kotamobagu dari tahun ke tahun belum mempunyai Standar Operating Procedures (SOP) yang jelas, dari sisi pengelolaan keuangan, penyerapan anggaran, maupun pemberi layanan kesehatan. walaupun sumber-sumber untuk melaksanakan suatu kebijakan tersedia atau para pelaksana mengetahui apa yang seharusnya dilakukan dan mempunyai keinginan untuk melaksanakan suatu kebijakan, kemungkinan kebijakan tersebut tidak dapat terlaksana atau terealisasi karena terdapatnya kelemahan dalam struktur birokrasi.

Saran yang dapat diberikan adalah:

1. Suatu entitas harus memiliki Sumber Daya Manusia (SDM) atau personal yang berkualitas dalam jabatan tertentu, pada waktu tertentu dan tempat tertentu agar tujuan implementasi kebijakan dapat tercapai. Komunikasi yang efektif serta sikap yang baik dari implementor sangat diperlukan dalam mewujudkan implementasi pemanfaatan dan pengelolaan keuangan dana kapitasi JKN oleh FKTP Kota Kotamobagu agar pelaksanaan program JKN dapat berjalan secara efektif dan efisien.

2. Harus memiliki struktur birokrasi yang jelas dan mempunyai Standar Operating Procedures (SOP) dana pengelolaan dana kapitasi JKN.

3. Dinas kesehatan sebagai atasan langsung dari FKTP dalam pemanfaatan dan pengelolaan keuangan dana kapitasi JKN, dalam proses perencanaan penyusunan anggaran harus lebih memaksimalkan kinerjanya agar supaya penyerapan anggaran akan sesuai dengan pagu anggaran yang ada serta meningkatkan koordinasi yang baik dengan pihak terkait.

\section{Daftar Pustaka}

Arikunto, Suharsimi. 2010. Prosedur Penelitian: Suatu Pendekatan Praktik. Rineka Cipta. Jakarta.

Bastian, Indra. 2015. Akuntansi Kesehatan. Jakarta: Erlangga

Creswell, John W. 2012. Educational research: planning, conducting, and evaluating quantitative and qualitative research. 4 th ed. p. cm. Pearson. University of Nebraska-Lincoln. 
Edward III, C George. 1980. Implementing Public Policy. Washington DC: Congressional Quartely Inc.

Edison Emron, Yohny Anwar, Imas Komariyah. 2016. Manajemen Sumber Daya Manusia. Cetakan kesatu. Bandung: Alfabeta.

Ibrahim. 2015. Metodologi Penelitian kualitatif. Bandung: Alfabeta

James H. Davis F. David Scoorman dan Lex Donalson. 1997. Toward a Stewardship Theory of Management." Academy of Management Review Vol.22, No.1, Page 2247,1997.

Lebacqz Karen. 1986. Teori - Teori Keadilan. Penerjemah Yudi Santoso, Bandung. Nusa Media.

Nugroho, Riant. 2014. Public Policy. Teori, Manajemen, Dinamika, Analisis, Konvergensi, dan Kimia Kebijakan. PT. Elex Media Komputindo. Kelompok Gramedia. Jakarta.

Peraturan Presiden No. 32 Tahun 2014 Tentang Pengelolaan Dan Pemanfaatan Dana Kapitasi Jaminan Kesehatan Nasional Pada Fasilitas Kesehatan Tingkat Pertama Milik Pemerintah Daerah.

Peraturan Menteri Kesehatan No. 19 Tahun 2014 Tentang Penggunaan Dana Kapitasi Jaminan Kesehatan Nasional Untuk Jasa Pelayanan Kesehatan Dan Dukungan Biaya Operasional Pada Fasilitas Kesehatan Tingkat Pertama Milik Pemerintah Daerah.

No. 21 Tahun 2016 Tentang Penggunaan Dana Kapitasi Jaminan Kesehatan Nasional Untuk Jasa Pelayanan Kesehatan Dan Dukungan Biaya Operasional Pada Fasilitas Kesehatan Tingkat Pertama Milik Pemerintah Daerah.

No. 28 Tahun 2014 Tentang Pedoman Pelaksanaan Program Jaminan Kesehatan Nasional.

Peraturan Menteri Keuangan No. 206 Tahun 2013 Tentang Tata Cara Penyediaan, Pencairan, dan Pertanggungjawaban Dana Iuran Jaminan Kesehatan Penerima Bantuan Iuran.

Profil Dinas Kesehatan Kota Kotamobagu Tahun 2017.

Sedarmayanti. 2003. Dasar - Dasar Pengetahuan Tentang Manajemen Perkantoran. Bandung: Mandar Maju.

Simbolan Anthon. 2006. Akuntabilitas Demokrasi Publik. Edisi Revisi. Yogyakarta: UGM.

Surat Edaran Menteri Dalam Negeri Nomor 900/2280/SJ Tahun 2014, Tentang Petunjuk Teknis Penganggaran, Pelaksanaan dan Penatausahaan, serta Pertanggungjawaban Dana Kapitasi Jaminan Kesehatan Nasional pada Fasilitas Kesehatan Tingkat Pertama Milik Pemerintah Daerah.

Subarsono. 2011. Analisis Kebijakan Publik (konsep. teori dan aplikasi). Pustaka Pelajar. Yogyakarta. Sugiyono. 2015. Memahami Penelitian Kualitatif. Bandung: Alfabeta.

Undang - Undang No.40 Tahun 2004 Tentang Sistem Jaminan Sosial Nasional. No.36 Tahun 2009 Tentang Kesehatan.

No.24 Tahun 2011 Tentang Badan Penyelenggaraan Jaminan Sosial. 